Sharif University of Technology
Scientia Iranica

\title{
Analytical method for optimal design of synchronous reluctance motor for electric scooter application
}

\author{
S.R. Salehinia, S.E. Afjei*, and A. Hekmati ${ }^{1}$ \\ Department of Electrical Engineering, Shahid Beheshti University, Tehran, Iran.
}

Received 27 July 2020; received in revised form 7 November 2020; accepted 4 January 2021

\section{KEYWORDS}

Flux barrier;

Taguchi method;

Flux lines;

Torque ripple;

Electric scooter.

\begin{abstract}
In recent years, Synchronous Reluctance Motor (SynRM) has caught the attention of many researchers and well-known companies specializing in designing and manufacturing electric motors due to its simplicity of application. In this regard, the current study aimed to present a comprehensive approach to design a series of SynRMs using both combined methods and finite element analysis and obtain an algorithm that functions based on the similarity between the flux lines and shape of flux barriers so as to obtain both maximum torque and minimum torque ripple. To this end, a SynRM was first designed for a specific electric vehicle. Then, the case studies with different numbers of flux barriers and poles were analyzed and optimized for each case. Finally, the optimal specifications of the motors in different cases were compared and the best one was selected. Accordingly, the design parameters were identified and optimized based on Taguchi method and then, the obtained results were evaluated through finite element analysis. To achieve both maximum torque and minimum torque ripple in the power range of 150 to 750 watts, three different poles with a constant number of slots (per pole per phase) at the same size for all the described motors were considered. The validity of the proposed method was confirmed by the experimental test results.

(C) 2022 Sharif University of Technology. All rights reserved.
\end{abstract}

\section{Introduction}

Synchronous Reluctance Motors (SynRMs) are characterized by a simple rotor structure $[1,2]$ because they do not require either a squirrel cage or permanent magnets in the rotor. Magnetic reluctance is the only factor that produces torque in the rotor according to the shape, position of flux barriers, and air gap. As a result, these parameters make the rotor design calculations complex. To improve the performance of the SynRM motor, use

1. Present address: Electric Machines Research Group, Niroo Research Institute, Tehran, Iran.

*. Corresponding author. Tel.: +9802122431803 E-mail addresses: s_salehinia@sbu.ac.ir (S.R. Salehinia); e-afjei@sbu.ac.ir (S.E. Afjei); Ahekmati@nri.ac.ir (A. Hekmati)

doi: $10.24200 /$ sci. 2021.56496 .4748 of auxiliary magnets to achieve high torque density has attracted a great deal of attention. A variety of rotor models with different forms of permanent magnet placement have been proposed for the betterment of the motor performance [3-5]. However, adding a permanent magnet will cause further problems such as cogging torque, strong armature reaction, and difficulty in assembling the motor. Studies that explore how to reduce the torque ripple in a reluctance synchronous motor can be generally divided into three categories. The first category comprises studies on the control methods [6,7], and second category contains studies that put their main focus on the design parameters, especially rotor design. The idea of choosing an asymmetric stator to reduce the torque ripple was suggested in [8]. In addition, displacing rotor poles and creating a rotor with asymmetric poles are the other approaches to reducing the torque ripple [9]. The studies in the 
third category suggest application of multi-objective optimization algorithms for the parametric design of motors with several barriers for optimal design, as shown in $[10,11]$.

Different methods have been proposed in the literature for rotor design such as designing based on the magnetic equivalent circuit [12-15] mathematical relationships and physical concepts $[16,17]$ and most recently, combining these relationships according to the sensitivity analysis of the involved parameters given in $[13,18,19]$. Given that rotor design parameters are complicated and time-consuming, the current study aims to investigate the most basic parameters with the greatest impact on the location and shape of the flux barriers to obtain the simplest and the most generalizable design. According to the studies [20-22], three design parameters including the flux barriers insulation ratio in the $q$ axis (defined as the ratio of the insulation layer to the rotor iron thickness), distance between the center of each barrier and motor shaft, and width of each barrier were found to have the greatest impact on the SynRM performance. Therefore, the positional arrangement of the barriers and their dimensions affect the saliency ratio and output parameters of the motor. This research also proposes a simple and general design method using these parameters to design a SynRM with different flux barriers based on the flux line distribution on the solid rotor.

A SynRM rotor was then optimized by determining the optimization target variables and defining a range of variables affecting the objective function using the Taguchi optimization method and a limited number of finite-element sensitivity analysis studies on the design parameters.

The main objective of this paper is to propose an optimal design method for reluctance synchronous motors. Designing different rotor topologies in a reluctance synchronous motor requires application of different mathematical calculation methods because the shapes of the flux barriers are mathematically defined based upon different curves. The equations that define these curves can be quite complex. In this paper, the shape of the magnetic flux barrier was designed based on the conformal mapping method. In addition, the main parameters affecting the shape of flux barriers on the output characteristic of the motor were identified based on these calculations using the Taguchi method and sensitivity analysis, as well. Average output torque and torque ripple were also nominated as design optimization targets. The critical point is the width and position of the flux barriers along the $q$ axis. In this regard, the effects of the number of motor poles, number of magnetic flux barriers, and shape and position of the flux barriers inside the rotor were investigated on the torque characteristic of the SynRM motor. Of note, the end-points of the flux barriers along the $d$ axis had a great impact on improving the output torque ripple. The effect of the defined parameters on the motor performance was also studied through the FEM method for all design cases. The main advantage of this method is its ability to reduce the number of experimented finite element analyses by considering the geometric parameters that are effective in designing the shape of flux barriers. Additionally, the sensitivity analyses of the $d$ axis parameters and Taguchi optimization method on the $q$ axis parameters, separately, prevent impossible combinations of the geometric parameters of the rotor. Finally, the final configuration of the motor was selected to be used in the electric scooter based on the analysis of the obtained results from the designs.

\section{SynRM rotor design}

The current research proposed an algorithm to design the rotor according to Figure 1. In the first step, an initial rotor is designed with the equations proposed in

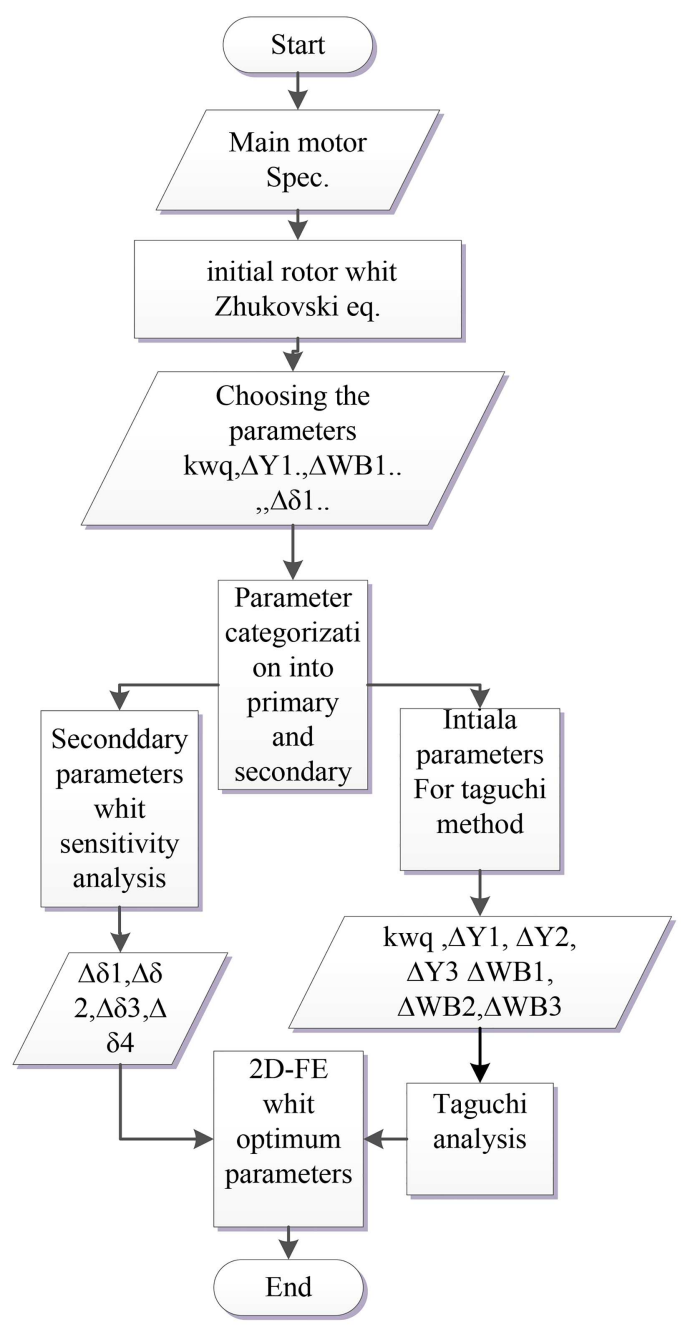

Figure 1. Flow-chart of the proposed design method. 
[18-21] which include (a) estimation of the flux barrier according to flux line distribution on the solid rotor and (b) determination of the width and position of flux barriers in the $q$ axis.

In the second step, the parameters affecting the output characteristics of the motor are selected, the motor is optimized to select the $q$ axis parameters, and the results are validated by both Taguchi method and finite element analysis. Finally, a comparison is made between the results from the mentioned methods. In the third step, the secondary $d$ axis parameters (endpoints of the flux barriers) that have a major impact on the torque ripple are selected. The obtained results are compared using the sensitivity analysis method to select the best case as the optimal rotor design. This process is repeated for different motors with the same dimensions and a number of different poles and flux barriers.

The gearbox ratio should also be determined to make the conversion of the maximum motor speed at nominal power into the maximum motor speed under field weakening condition feasible. For the selected scooter dimensions, the gearbox ratio is as follows [22]:

$$
G=\frac{\omega_{\text {Max }- \text { Motor }}}{\omega_{\text {Max-wheel }}}, \quad G<10 .
$$

Therefore, the maximum torque at a low speed is given by:

$$
T_{\text {Max }}=G \frac{P_{\text {rated }}}{\omega_{\text {Max }- \text { motor }}}
$$

where $G$ is the gearbox ratio and $P_{\text {rated }}$ the power of the motor.

First, to determine the torque and speed of the scooter, the required force by the scooter is calculated through the following equation:

$$
F_{T}=F_{r}+F_{a d}+F_{h}+F_{a}
$$

where $F_{T}$ is the total driving force, $F_{r}$ the rolling resistance force, $F_{a d}$ the aerodynamic drag force that is related to the shape of the scooter, $F_{h}$ the force to overcome the scooter weight as well as the slope gravity the scooter should pass, and $F_{a}$ the acceleration force in the scooter, which is a linear force.

The values of the forces that the scooter must overcome can be obtained as follows [23]:

$$
\begin{aligned}
& F_{r}=\mu_{r} m g, \\
& F_{a d}=0.5 \rho A C_{d} g v^{2}, \\
& F_{h}=m g \sin (\varphi), \\
& F_{a}=m a,
\end{aligned}
$$

where $\mu_{r}$ is the rolling resistance coefficient ( 0.015 for the scooter tire), $m$ the vehicle portable weight (60 $\mathrm{kg}), g$ the gravity factor $\left(9.8 \mathrm{~m} / \mathrm{s}^{2}\right), \rho$ the density of air $\left(\mathrm{kg} / \mathrm{m}^{3}\right), A$ the area of the front part of the scooter $\left(0.6 \mathrm{~m}^{2}\right), C_{d}$ the vehicle aerodynamic coefficient $(0.7)$, $v$ the velocity of the vehicle $(10 \mathrm{~km} / \mathrm{h}), \phi$ slope of the road, and $a$ the acceleration.

As shown in Figures 2 and 3, a motor with the power of $0.15 \mathrm{~kW}$ is chosen to move a weight of 60 $\mathrm{kg}$ at the maximum speed of $20 \mathrm{~km} / \mathrm{h}$ on a zero-slope road and similarly, a motor with a power of $0.3 \mathrm{~kW}$ is required on a road with a slope of 10 degrees at the maximum speed of $10 \mathrm{~km} / \mathrm{h}$. In this respect, the mechanical structure of Figure 4 is considered with a diverse number of poles for a certain power range $(0.15$ $\mathrm{kW}$ to $0.75 \mathrm{~kW}$ ).

Tables 1 and 2 present the general specifications used for the initial motor design and all study cases, respectively.

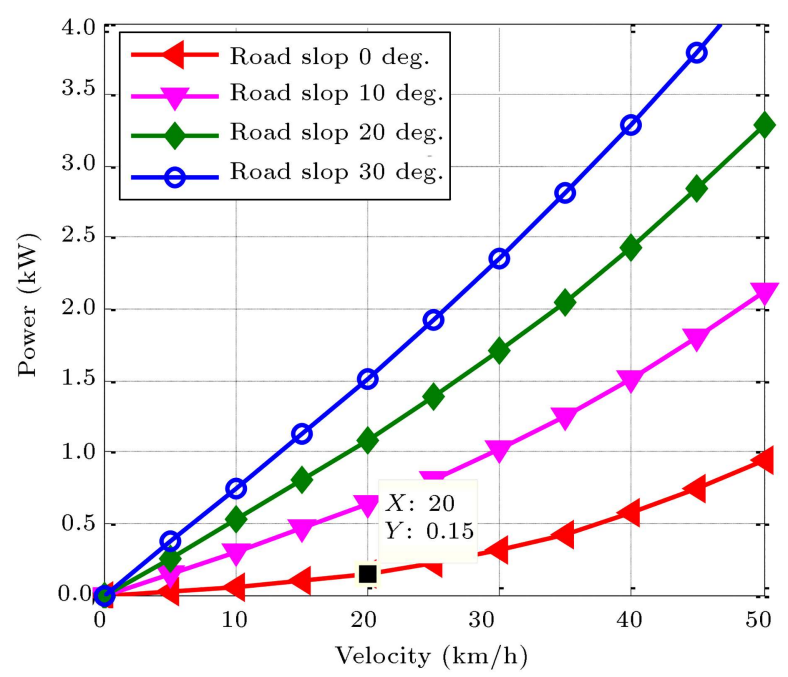

Figure 2. Required torque-speed characteristics for the electric scooter on different road slopes.

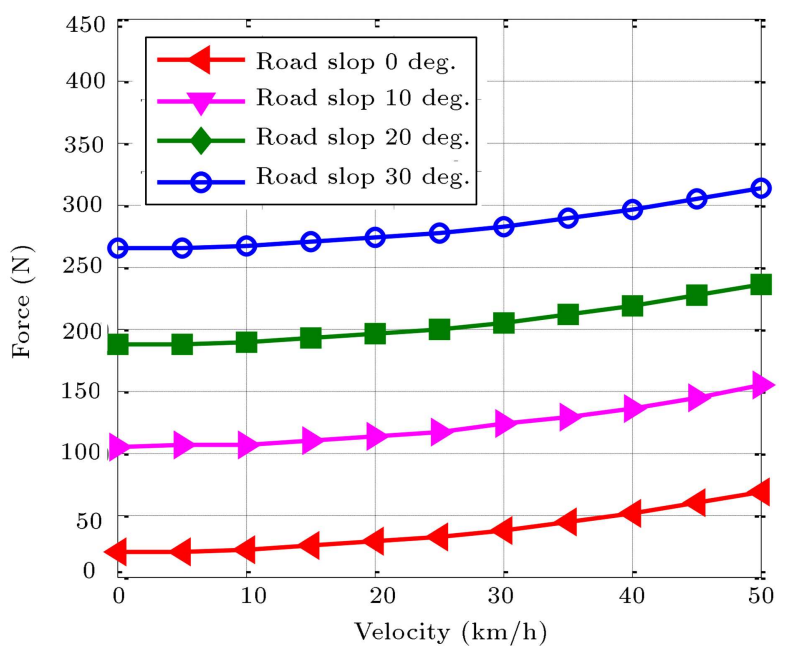

Figure 3. Force-speed characteristics of the electric scooter on different road slopes. 


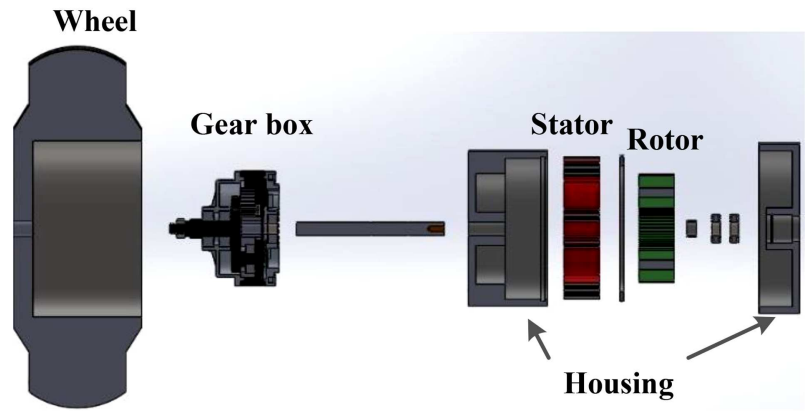

Figure 4. An exploded view of the SynRM and Gearbox.

Table 1. General specifications of the motors.

\begin{tabular}{lll}
\hline Parameter & Definition & Value \\
\hline$P_{o}$ & Range of power & $0.15-0.75 \mathrm{~kW}$ \\
$N_{s}$ & Rated speed & $1500(\mathrm{rpm})$ \\
$D_{O S}$ & Stator outside diameter & $150(\mathrm{~mm})$ \\
$D_{O R}$ & Rotor outside diameter & $90(\mathrm{~mm})$ \\
$P . F$ & Power factor & 0.7 \\
$\boldsymbol{\eta}$ & Motor efficiency & 0.85 \\
$M a$ & Stator and rotor material & M27-24 \\
$L$ & Stack length & $42(\mathrm{~mm})$ \\
$I_{P}$ & Phase current & $9.5(\mathrm{~A})$ \\
$G$ & Gearbox ratio & 9.45 \\
$k_{s t}$ & Laminations stacking factor & 0.95 \\
\hline
\end{tabular}

Table 2. Characteristics of study cases.

\begin{tabular}{cccc}
\hline Parameter & $\begin{array}{c}\text { Number of } \\
\text { pole }\end{array}$ & $\begin{array}{c}\text { Number of } \\
\text { barriers }\end{array}$ & $\begin{array}{c}\text { Number of } \\
\text { slot stator }\end{array}$ \\
\hline Case 1 & 4 & 3 & 24 \\
Case 2 & 4 & 4 & 24 \\
Case 3 & 6 & 3 & 36 \\
Case 4 & 6 & 4 & 36 \\
Case 5 & 8 & 3 & 48 \\
Case 6 & 8 & 4 & 48 \\
\hline
\end{tabular}

\section{Matematical approach}

The proven rules in the fluid dynamics are suggested to be followed in order to achieve maximum flux in the $d$ axis and block the flux in the $q$ axis, which is also the main purpose of all rotor designs. This leads to an increase in the saliency ratio which is defined as the ratio of the $d$ axis inductance to the $q$ axis inductance. To better understand the matter, the distribution of the flux lines on a simple and solid rotor without any flux barriers is shown in Figure 5 .

The best and most effective way to block the fluid flow is to put the barriers perpendicular to the fluid path. Here, the flux lines are considered as the fluid flow. Accordingly, to provide the maximum barriers

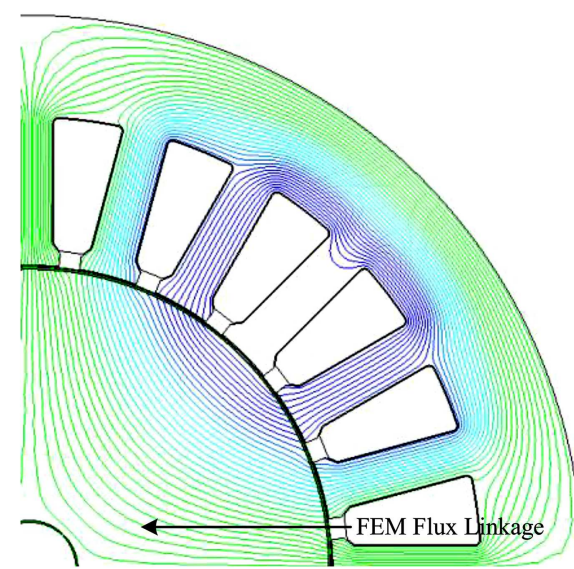

Figure 5. Distribution of flux lines in a solid rotor.

for the flux lines of the $q$ axis, the barriers along the $q$ axis are assumed to be perpendicular. The application of this method would lead to different shapes of the flux barrier that depends on the insulation ratio of $d$ and $q$ axes, number of flux barriers, distance between the flux barriers, thickness of each barrier, and end-points of the barrier flux. The barrier along the $d$ axis should be parallel to the $d$ axis flux lines and perpendicular to the $q$ axis flux lines as much as possible.

According to [21], selection of the barriers along the $q$ axis directly affects the average value of torque, and both the shape and position of the barriers along the $d$ axis have a major impact on the degree of torque ripple.

\section{A: Shape of the flux barriers in rotor}

Based on the concept of simple congruent mapping in the complex analysis theory and Zhukovski function, Eq. (8) can be written as in the following $[12,19]$ :

$$
f(z)=\left(z+\frac{a}{z}\right)^{2}=z^{2}+2 a+\frac{a^{2}}{z^{2}}
$$

where $z=x+j y$ is a complex variable; and by dividing the real and imaginary parts of the function $f(z)$, the imaginary part can be written as:

$$
2 x y \frac{2 x y w^{2}}{x^{2}+y^{2}}=v,
$$

where $w$ and $v$ are real variables that can be changed to obtain different Zhukovski curves. It should be noted that the analytical solution of Eq. (9) can be complicated; therefore, using parametric equations is the simplest way to explain the Zhukovski curves $[23,24]$ :

$$
\begin{aligned}
& x^{2}+y^{2}=r_{d}(\alpha, w, v), \\
& \frac{y}{x}=\tan (\alpha) .
\end{aligned}
$$

Eqs. (10) and (11) can be integrated into Eq. (9). 
As a result, Zhukovski parametric equations can be expressed as follows:

$$
\left\{\begin{array}{l}
x=r_{d}(\alpha, w, v) \cos (\alpha) \\
y=r_{d}(\alpha, w, v) \sin (\alpha)
\end{array}\right.
$$

As already mentioned, the flux lines in the $d$ and $q$ axes are orthogonal. Therefore, all of the orthogonal curves on the $d$ axis flux curves can be shown by the real part of $f(z)$ :

$$
2 w+x^{2}-y^{2}+\frac{\left(x^{2}-y^{2}\right) w^{2}}{\left(x^{2}+y^{2}\right)^{2}}=u .
$$

Eqs. (3) and (4) can be integrated into Eq. (6) to calculate one of the parameters of Eq. (5) such as radius. Hence, the orthogonal curves can be calculated according to the radius of the following Eqs. $[22,23]$ :

$$
r_{d}=\sqrt{\frac{u-2 w+\sqrt{(2 w-u)^{2}-4 w^{2}(\cos (2 \alpha))^{2}}}{2 \cos (2 \alpha)}} .
$$

According to Eq. (14) based on which the radius is calculated, the radius has a direct and binary relation with the angle $\alpha$, and the two parameters $w$ and $v$ are the two variables. However, the parametric equations are better than Eq. (2) in determining the shape of the flux barriers which should be solved numerically. Based on the equations of the barrier curves through which the flux lines pass as well as Eqs. (13) and (14), the flux paths in the rotor can be written as:

$$
r(\theta)=\left(\frac{D_{\text {shaft }}}{2}\right) \sqrt[p]{\frac{C+\sqrt{C^{2}+4 \cdot \sin ^{2}(p \theta)}}{2 \cdot \sin (p \theta)}}
$$

where $p$ is the rotor number of pair of poles, $r$ the radius passed through the rotor center, $\theta$ the mechanical angle of the $d$ axis in the polar coordinate (the cylindrical coordinate system), $D_{\text {shaft }}$ the motor shaft diameter, and $C$ a constant which is a function of the points where the flux lines are passing through. According to the above equations, these curves can be represented by $\theta(r)$ according to the following equation:

$$
\theta(r)=\frac{1}{p} \cdot \sin ^{-1}\left[\frac{C \cdot\left(\frac{r}{\left(D_{\text {shaft } / 2}\right)}\right)^{p}}{\left(\frac{r}{\left(D_{\text {shaft } / 2}\right)^{2 p}-1}\right)}\right] .
$$

The constant $C$ can be calculated using Eq. (16) by considering the angle and radius in the following equation:

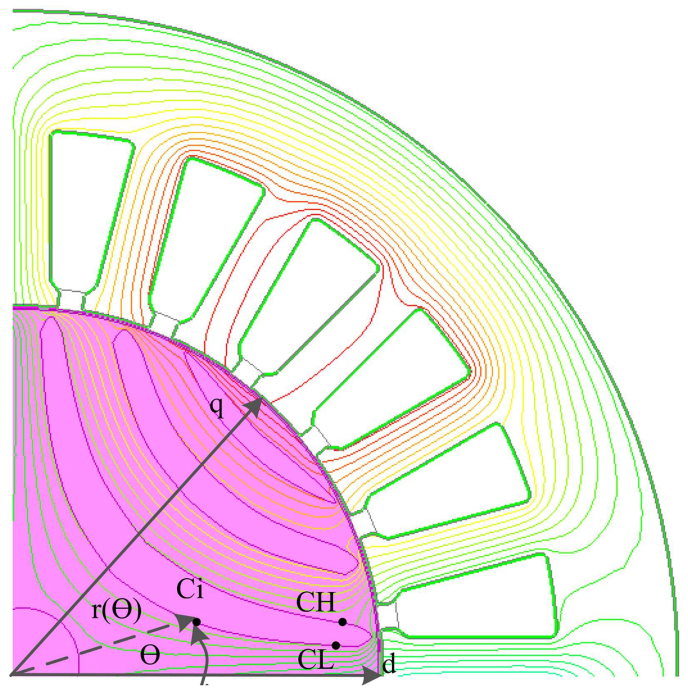

Figure 6. Geometry definition of the flux lines in a four-pole motor.

$$
c=\frac{\sin (p \theta) \cdot\left[\left(\frac{r}{\left(D_{\text {shaft } / 2}\right)}\right)^{2 p}-1\right]}{\left(\frac{r}{\left(D_{\text {shaft } / 2}\right)}\right)^{p}} .
$$

Eqs. (8)-(17) are used in the first step of the rotor design. The beginning and end-point of each flux barrier on the $q$ axis are calculated according to the rules given in the next section. As shown in Figure 6, the barrier shape is determined by determining the value for parameter $C$ for each flux path, which is the same for all of the points of the path, and also calculating the angles or radii of the next points.

B: Calculating the width of the flux along the $q$ axis This section delves into the calculation of the width of the flux barriers along the $q$ axis.

As seen in Figure 7, the coordinates of points $P B j$ should be specified along the $q$ axis where $B$ represents the barriers, $j$ the number of points in the rotor, $\delta_{i}$ the opening angle of the selected $i$ th barrier layer, and $i$ the number of the flux barriers. To determine these points, first, the number of flux barriers and insulation ratio should be determined. The insulation ratio on the $q$ axis is defined as the ratio of the flux barrier thickness along the $q$ axis to the iron thickness in rotor along the $q$ axis, $k_{w q}[18-20]$.

The width of the flux barriers and iron sections along the $q$ axis is calculated through the equations given in [21,26-29]. This rule is expressed by Eq. (18):

$$
\begin{aligned}
& \frac{W B_{k}}{W B_{m}}=\frac{\Delta f_{k}}{\Delta f_{m}} \sqrt{\frac{S_{b k}}{S_{b m}}}, \\
& \Delta f_{k}=f_{q+1}-f_{q k},
\end{aligned}
$$




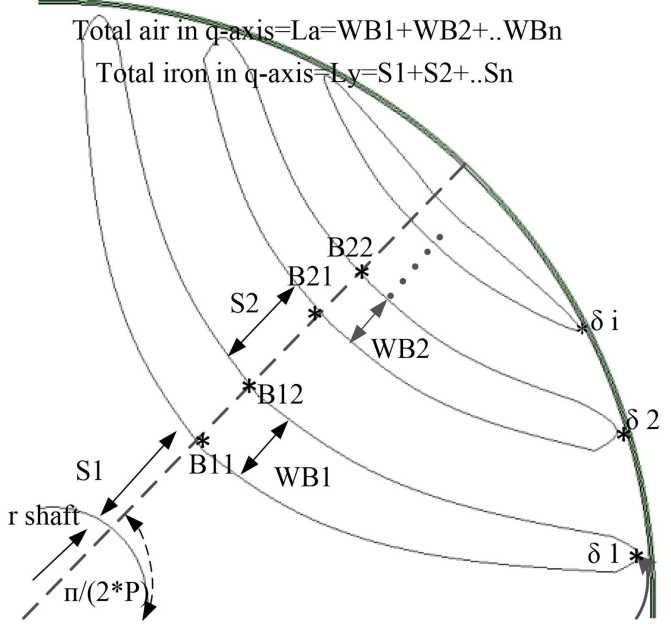

Figure 7. Geometrical view of the proposed rotor with known design parameters.

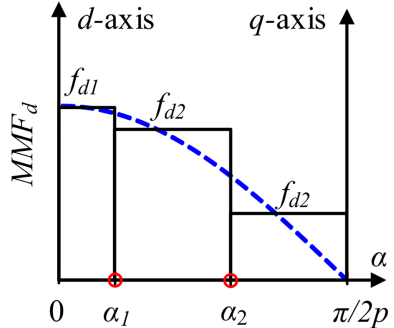

(a)

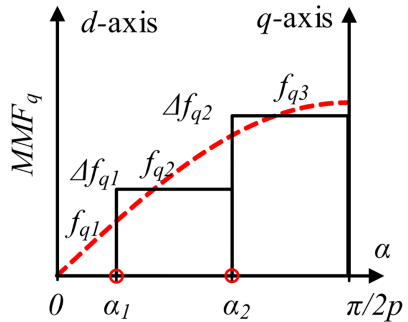

(b)
Figure 8. Distribution diagram of the magneto-motive force of a half pole of the rotor [25].

where $k$ and $m$ denote the number of the flux barriers, $\Delta f_{k}$ is the per-unit Magnetomotive Force (MMF) mean difference, and $S_{b k}$ is the length of the $k$ th barrier (Figure 8).

The main parameters needed for designing and locating the flux barriers in the rotor are as follows:

(a) The distances between the flux barriers represented by $\left(S_{k}\right)$;

(b) The thickness of the flux barriers along the $q$ axis represented by $\left(W B_{k}\right)$ (see Figure 6$)$.

As suggested in $[21,23,30]$, if the difference between the numbers of stator slots per pair of poles $(n s)$ and rotor slots per pair of poles $(n r)$ equals \pm 4 , a more reasonable result will be obtained $[29,30]$. The distance between the flux barriers $\left(S_{k}\right)$ is calculated through Eq. (20):

$$
\frac{2 S_{1}}{S_{2}}=\frac{f d_{1}}{f d_{2}}, \frac{S_{h}}{S_{h+1}}=\frac{f d_{h}}{f d_{h+1}}
$$

where $f d_{h}$ is the magnetomotive force along the $d$ axis and $h=2, \cdots, K$ [29].

According to Figure 8(b), the magnetomotive force along the $d$ axis in each segment is equal to the mean value of the magnetomotive force by that segment. Therefore, $f d_{k}$ is calculated by averaging the magnetomotive forces between the two endpoints of the segment $k$ th $[10,18,21,25,27]$.

\section{Sequential subspace multi-objective optimization of SynRM}

Followed by the initial rotor design, seven geometric variables were selected to be analyzed to optimally design the rotor. The simplified topology of the rotor is depicted in Figure 4 where the design variables are $Y_{q i}$ (the distance between the center of the magnetic barriers along $q$ axis and rotor), $W B_{i}$, and $k_{w q}$. Followed by summarizing the selected parameters, there are still seven variables involved in designing the rotor in all design cases. Each of the variables is evaluated at three equal levels. The specific values of each level, such as Case 1, are shown in Table 3.

All of the cases require $3^{7}=2187$ experiments for each motor, which is a considerable number. In this respect, the Taguchi method is employed to determine the optimum values of the rotor variables.

The orthogonal test table of L27 (3) is shown in Table 4. Having the obtained optimum point, the required modifications to achieve the optimal point are applied and the results are simulated; then, the values obtained from the Taguchi method are compared with these results. Finally, the optimal combination of the factor levels and average torque and torque ripple values at the optimum point is calculated.

The main objective here is to simultaneously optimize these two results (maximum value for the average torque and minimum value for the torque ripple); therefore, the analysis of variance should be used to find the optimal combination. Analysis of variance helps evaluate the contribution of each factor to the distribution of the total responses. To this end, the sum of squares is calculated for each factor according to Eqs. (21)-(23) [31]:

$$
T=\sum_{i=1}^{n} y_{i}
$$

Table 3. Each levels of design variables.

\begin{tabular}{lccc}
\hline Variables level & Level 1 & Level 2 & Level 3 \\
\hline$k_{w q}$ & 0.4 & 0.5 & 0.6 \\
$\Delta Y q_{1}(\mathrm{~mm})$ & 0 & 1.5 & 3 \\
$\Delta Y q_{2}(\mathrm{~mm})$ & -1 & 0 & 1 \\
$\Delta Y q_{3}(\mathrm{~mm})$ & -1 & 0 & 1 \\
$\Delta W B_{1}(\mathrm{~mm})$ & -1 & 0 & 2 \\
$\Delta W B_{2}(\mathrm{~mm})$ & -1 & 0 & 2 \\
$\Delta W B_{3}(\mathrm{~mm})$ & -1 & 0 & 2 \\
\hline
\end{tabular}


Table 4. Experimental plan of $127(37)$.

\begin{tabular}{cccccccc}
\hline Variables level & $\boldsymbol{k}_{\boldsymbol{w} \boldsymbol{q}}$ & $\boldsymbol{Y} \boldsymbol{q}_{\mathbf{1}}$ & $\boldsymbol{Y} \boldsymbol{q}_{\boldsymbol{2}}$ & $\boldsymbol{Y} \boldsymbol{q}_{\boldsymbol{3}}$ & $\boldsymbol{W} \boldsymbol{B}_{\mathbf{1}}$ & $\boldsymbol{W} \boldsymbol{B}_{\boldsymbol{2}}$ & $\boldsymbol{W} \boldsymbol{B}_{\boldsymbol{2}}$ \\
\hline 1 & 1 & 1 & 1 & 1 & 1 & 1 & 1 \\
2 & 1 & 1 & 1 & 1 & 2 & 2 & 2 \\
3 & 1 & 1 & 1 & 1 & 3 & 3 & 3 \\
& & & & & & & \\
25 & 3 & 3 & 2 & 1 & 1 & 3 & 2 \\
26 & 3 & 3 & 2 & 1 & 2 & 1 & 3 \\
27 & 3 & 3 & 2 & 1 & 3 & 2 & 1 \\
\hline
\end{tabular}

Table 5. Taguchi optimization results.

\begin{tabular}{lcccccc}
\hline Parameter & Case 1 & Case 2 & Case 3 & Case 4 & Case 5 & Case 6 \\
\hline$T_{\text {avg }}$ (N.m) & 1.04 & 0.88 & 0.59 & 1.04 & 0.48 & 0.58 \\
& & & & & & \\
$T_{\text {Ripple }}(\%)$ & 36.96 & 27.84 & 22.17 & 34.18 & 28.80 & 16.31 \\
\hline
\end{tabular}

$$
\begin{aligned}
& S S_{A}=\frac{1}{t} \sum_{i=1}^{m} A_{i}^{2}-\frac{1}{n} T^{2}, \\
& S S_{T}=\sum_{i=1}^{n} y_{i}^{2}-\frac{1}{n} T^{2},
\end{aligned}
$$

where $m$ is the number of levels of factor $A, n$ the total number of performed experiments, $A_{i}$ the sum of outputs corresponding to the $i$ th level of factor $A, t$ the number of experiments performed at the $i$ th level of factor $A, T$ the sum of the outputs of all experiments, $y_{i}$ the output of the $i$ th experiment, and $S S_{T}$ the sum of the squares.

$$
\begin{aligned}
Y_{W L 1_{\text {Level } 3}=} & \frac{1}{9} *\left(T_{a v g}(3)+T_{a v g}(6)+T_{a v g}(9)\right. \\
& +T_{a v g}(12)+T_{a v g}(15)+T_{a v g}(18) \\
& \left.+T_{a v g}(21)+T_{a v g}(24)+T_{a v g}(27)\right)
\end{aligned}
$$

Eq. (24) is employed to calculate the mean effect of the $i$ th level of the $j$ th factor on the torque and torque ripple. For example, to calculate the mean effect of the third level of the $W B_{1}$ factor among all experiments, the results of the third coefficients $(3,6,9,12,15$, $18,21,24$, and 27) are obtained. The same procedure is calculated for the mean effect of the levels of other factors on the target function. In order to select the optimal combination in the tests based on the Taguchi method, the Signal-to-Noise ratio $(S / N)$ is taken into consideration. Of note, the $S / N$ values are calculated for each level separately. Firstly, according to thelarger-the-better scenario, the $S / N$ ratio is defined as follows [32]:

$$
S / N=-10 \log _{10}\left(n^{-1} \sum_{i=1}^{n} y^{-2}\right) .
$$

Secondly, according to the-smaller-the-better scenario, the $S / N$ ratio is defined as follows:

$$
S / N=-10 \log _{10}\left(n^{-1} \sum_{i=1}^{n} y^{2}\right) .
$$

Subsequently, the optimal case of motors is determined through the Taguchi method. Table 5 shows the optimized values of the average torque and torque ripple based on the Taguchi method. According to the results, increasing the number of poles decreases the torque ripple.

\section{Sensitivity analysis of the motors using finite element method}

The variables including $\delta_{i}$ are measured through the sensitivity analysis of their effects on the design optimization based on the Taguchi method. The optimal combinations are then selected to obtain maximum average torque and minimum torque ripple. Followed by determining the optimum composition for each motor case, the results from the Taguchi method are computed under these new conditions and compared with those from the initial simulation. Table 6 shows the results of both initial and optimized cases.

As observed in Table 6, a comparison of the simulation results revealed that the average torque increased in all of the cases. For instance, the average torque of the optimal design in Case 5 was enhanced by $19 \%$ and the torque ripple in Case 2 was reduced by $49 \%$. Figure 9 lists the torques of all optimal cases.

To select the best case and have a better understanding of the performance of the motors, the average 
Table 6. The comparison of the results for all the cases.

\begin{tabular}{cccccccc}
\hline \multirow{2}{*}{$\begin{array}{c}\text { Study } \\
\text { cases }\end{array}$} & \multicolumn{2}{c}{ Average torque } & $\begin{array}{c}\text { Initial } \\
\text { design }\end{array}$ & $\begin{array}{c}\text { Taguchi } \\
\text { design }\end{array}$ & $\begin{array}{c}\text { Optimal } \\
\text { design }\end{array}$ & & \multicolumn{3}{c}{ Torque ripple (\%) } \\
design & $\begin{array}{c}\text { Taguchi } \\
\text { design }\end{array}$ & $\begin{array}{c}\text { Optimal } \\
\text { design }\end{array}$ \\
\hline Case 1 & 0.99 & 1.04 & 1.10 & & 56.40 & 36.96 & 36.05 \\
Case 2 & 0.88 & 0.88 & 0.88 & & 39.46 & 27.84 & 26.33 \\
Case 3 & 0.54 & 0.59 & 0.64 & & 30.16 & 22.17 & 12.19 \\
Case 4 & 0.66 & 1.04 & 0.73 & & 21.06 & 34.18 & 25.36 \\
Case 5 & 0.47 & 0.48 & 0.58 & & 30.44 & 28.8 & 28.47 \\
Case 6 & 0.58 & 0.58 & 0.66 & & 17.2 & 16.31 & 14.31 \\
\hline
\end{tabular}

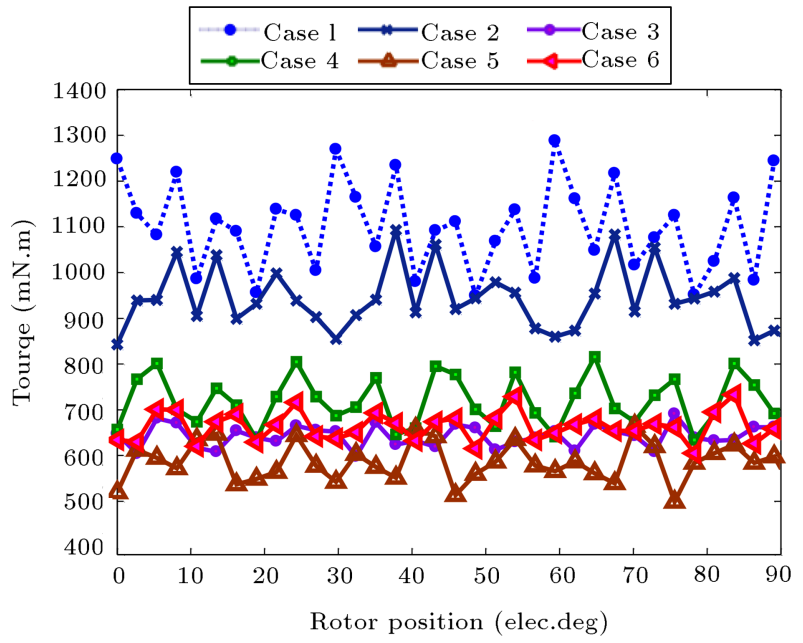

Figure 9. Torque of all motors in the optimized cases.

torque and torque ripple of the motors in all cases are shown in Figure 10. According to the obtained results, followed by compromising between the results and also considering the average torque and torque ripple values simultaneously, Case 2 is selected as the best one. In addition, the torque can be generally calculated using Eq. (27), as shown below:

$$
T_{a v g}=\frac{3}{2} \frac{p}{2}\left(L_{d}-L_{q}\right) \cdot I^{2} \cdot \sin (2 \theta),
$$

where $p$ is the number of rotor poles, $L_{d}$ the inductance value in the $d$ axis, $L_{q}$ the inductance value along the $q$ axis, $I$ the stator peak current, and $\theta$ the current angle.

According to Eq. (27), the amount of torque is related to both numbers of rotor poles and the difference between the $d$ and $q$ axes which are directly related to both motor saliency ratio and stator current.

Figure 11 shows the inductance values of the $d$ and $q$ axes and their difference, and Figure 12 presents the saliency ratio of all motors. According to the obtained results, an increase in the number of poles does not necessarily ensure torque improvement because it leads to inductance difference reduction and saliency ratio.

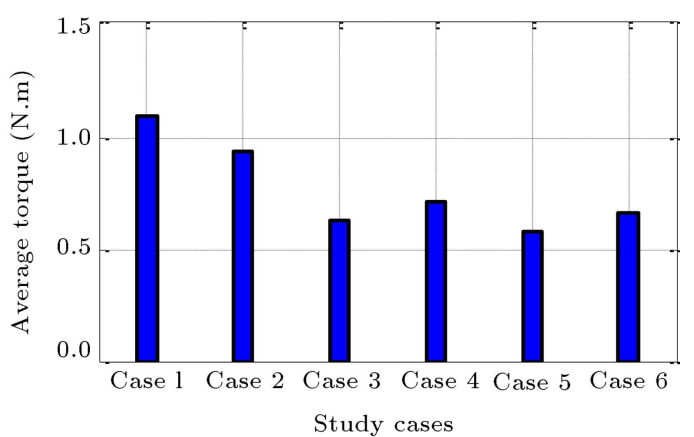

(a)

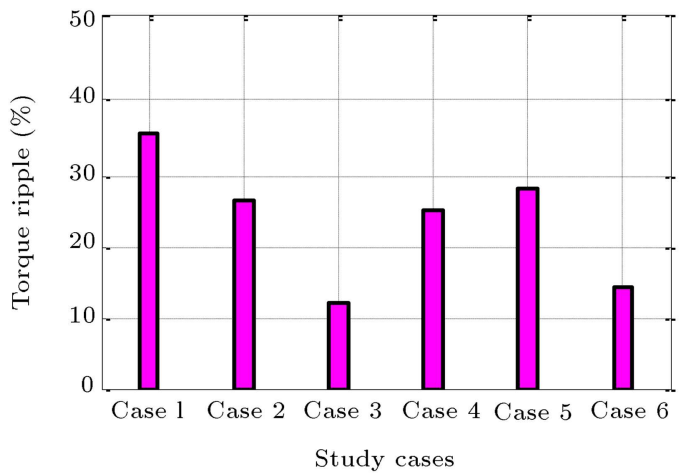

(b)

Figure 10. Torque characteristics: (a) Average torque and (b) Torque ripple of all cases in optimization.

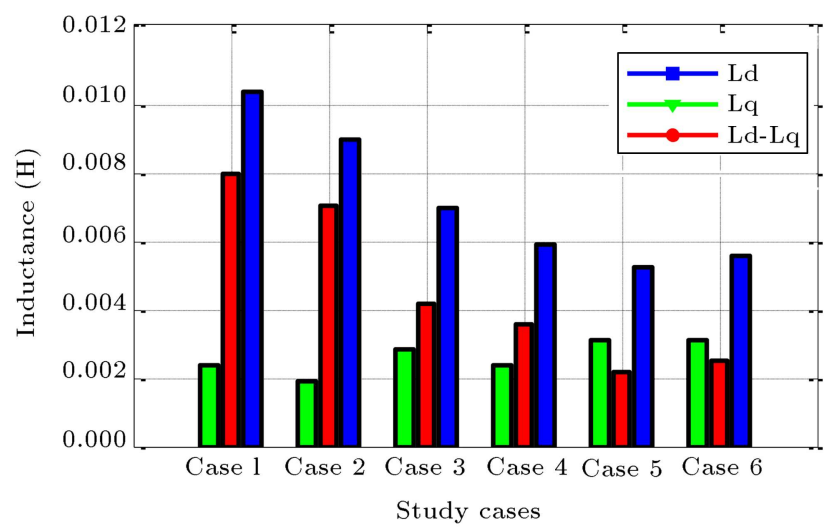

Figure 11. Inductance and the inductance difference for the $d$ and $q$ axes. 


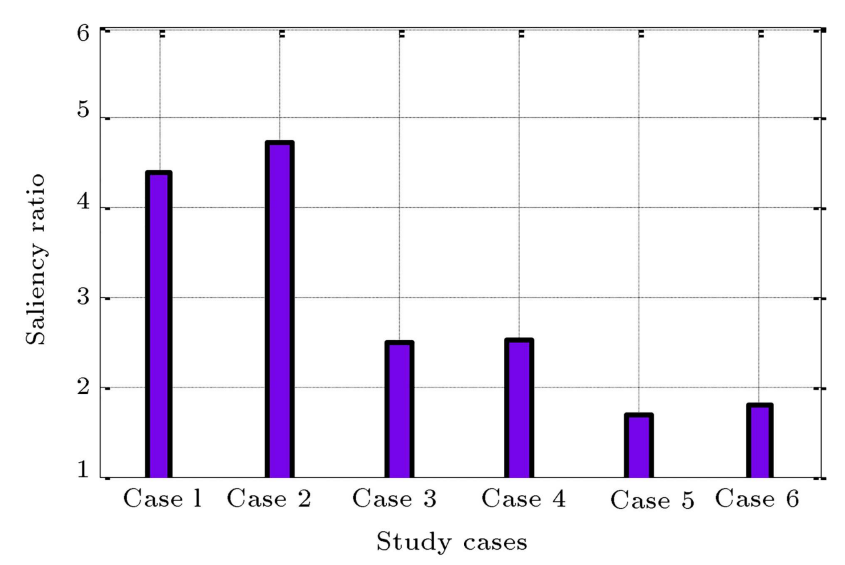

Figure 12. The saliency ratio in all cases.

\section{Electrical characteristics evaluation}

The highest inductance difference in Figure 11 isattributed to Case 1, and the effect of this value is large enough to affect the number of pole pairs. Further, different values of the current amplitude are taken into account. The stator current amplitude ranging from 9 Amps to 25 Amps is examined in all cases. The resultant torque is given in Figure 13.

According to the obtained results, although upon increasing the stator current, the average torque value is leveled up in all cases (see Figure 13(a)), and the low levels of torque ripple are related to Case 3 and Case 6 (Figure 13(b)) which are four and eight pole cases, respectively (Table 2). In conclusion, by considering the average torque and the torque ripple of all the experiments obtained through the finite element method, at high values of current, the best torque with the lowest torque ripple is obtained in Case 6 which is formed of an eight-pole motor with four flux barriers. For the selected Cases 2 and 6, the torque-current-angle surfaces are shown in Figure 14(a) and (b), respectively. In addition, the flux line distributions of two cases at 9 Amps (low power) for Case 2 and at 20 Amps (high power) for Case 6 are shown in Figure 15(a) and (b), respectively.

\section{Selecting an optimal design}

In this section, based on the provided results, the process of designing the optimal rotor is presented.

According to Table 6, by using the proposed method, in comparison with the initial design, the average torque is increased by $19 \%$ in the eight-pole motor with three flux barriers and the torque ripple is reduced by $20.4 \%$ in the four-pole motor with three flux barriers. Then, through the general equation of the SynRM torque, the experiment is performed at different current values, and it is shown that due to the relationships among the parameters affecting the motor torque and by changing the current in each case, the

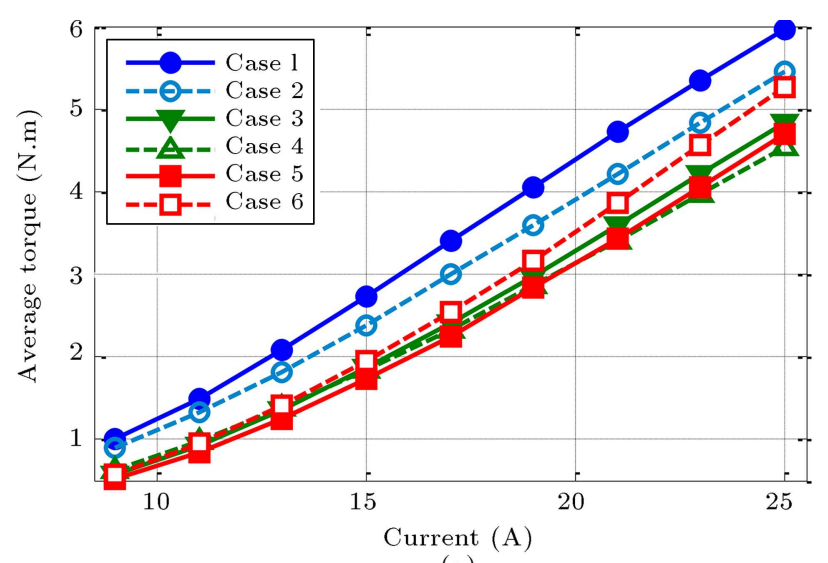

(a)

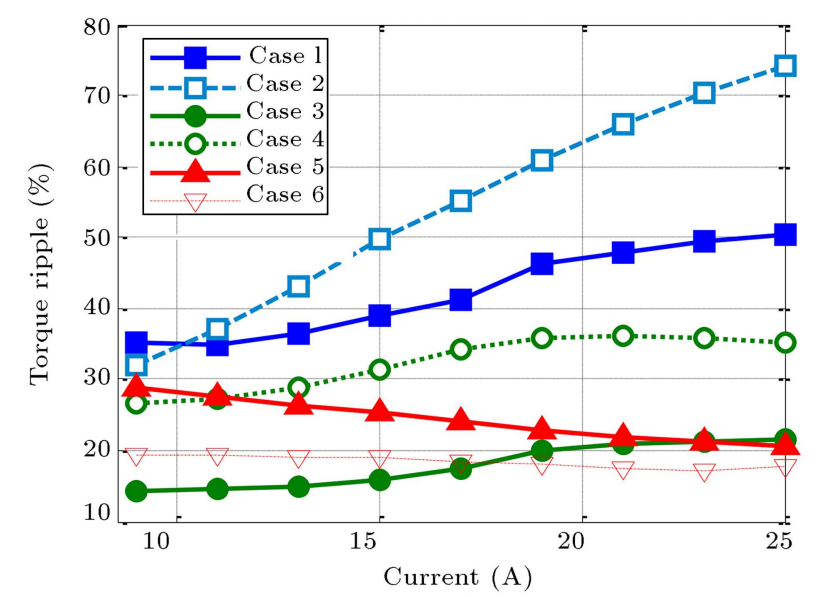

(b)

Figure 13. Torque-current characteristic for the all optimized cases.

motor reaches maximum torque with an appropriate ripple at a particular current. In this regard, sixpole motors with three flux barriers have the best performance at currents lower than 12 Amps and also at 300 watts of power, and eight-pole motors with four flux barriers have the best performance in higher currents and powers up to 750 watts.

Based on the result given in Figure 13, to produce the highest average torque with the lowest torque ripple at currents less than $15 \mathrm{~A}$, a motor with six poles is an appropriate choice. Therefore, a motor with six poles is selected as the final design. To optimize the motor by the Taguchi method [31,32], the number of optimization factors and the levels of design variables are selected for the design where the control factors as well as the selected levels are shown in Table 7 .

In the next step, an appropriate orthogonal array is selected and the matrix is constructed where the recommended experiments are arranged based on the Taguchi method. The results of the indicated tests are then analyzed to determine the appropriate levels for each factor. As shown in Table 8 and based on this arrangement, 25 tests should be carried out totally for five factors at five levels. 


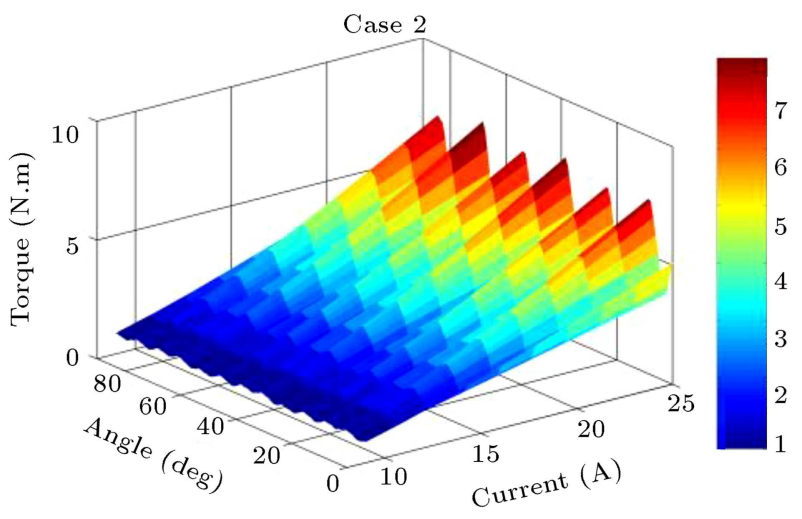

(a)

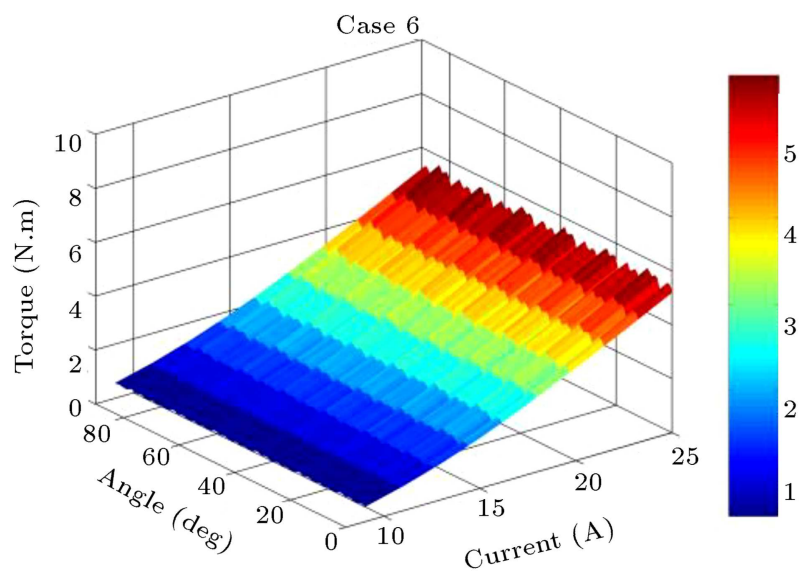

(b)

Figure 14. Torque of optimized motors at input currents from 9 Amps to 25 Amps: (a) Case 2 and (b) Case 6.

Table 7. Different levels of design variables.

\begin{tabular}{lccccc}
\hline Variable & Level & Level & Level & Level & Level \\
& $\mathbf{1}$ & $\mathbf{2}$ & $\mathbf{3}$ & $\mathbf{4}$ & $\mathbf{5}$ \\
\hline$\Delta Y q_{1}$ & -0.75 & -0.5 & 0 & 1 & 2 \\
$\Delta Y q_{2}$ & -2 & -1 & 0 & 0.5 & 1 \\
$\Delta W B_{1}$ & -1 & -0.5 & 0 & 0.5 & 1 \\
$\Delta W B_{2}$ & -1 & -0.5 & 0 & 0.5 & 1 \\
$k_{w q}$ & 0.3 & 0.4 & 0.5 & 0.6 & 0.7 \\
\hline
\end{tabular}

As shown in Figure 16(a), the results obtained from the average torque and torque ripple calculations indicate that the maximum average torque is achieved by selecting $\Delta Y q_{1}$ and $k_{w q}$ at the fourth level, $\Delta Y q_{2}$ at the second level, and $W B_{1}$ and $W B_{2}$ at the fifth level. As observed in Figure 16(b), the lowest torque ripple value is obtained by selecting $\Delta Y q_{1}, \Delta Y q_{2}$, and $W B_{1}$ at the first level, $k_{w q}$ at the second level, and $W B_{2}$ at the fifth level.

As observed in Figure 16(a) and (b), to select the appropriate levels of factors, it is necessary to have an index to evaluate the effect of each factor on the optimization objective function. To this end, the analysis

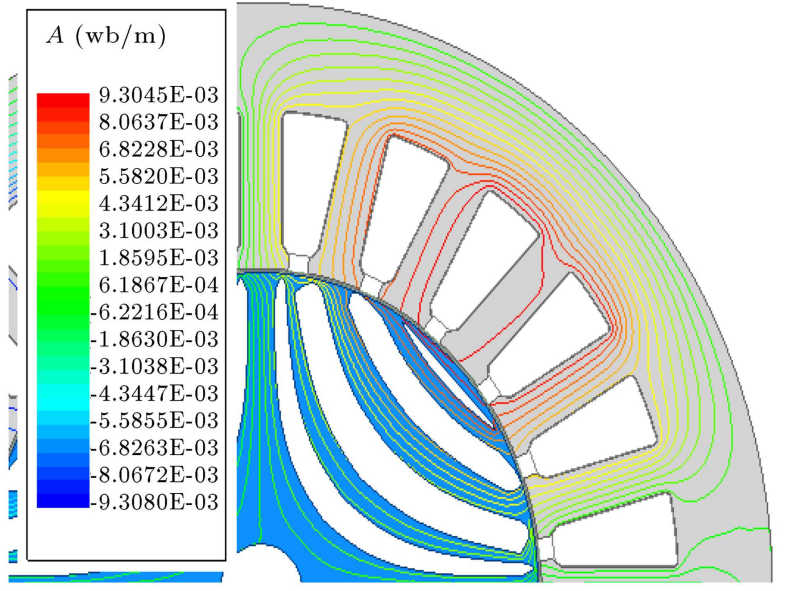

(a)

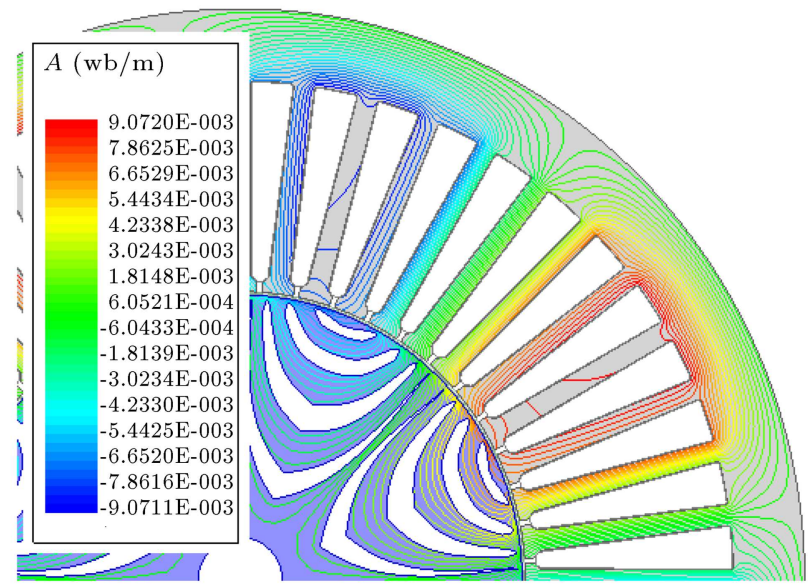

(b)

Figure 15. (a) Linkage flux lines in motor of Case 2 at 9 Amps. (b) Motor of Case 6 at 20 Amps.

of variance was employed which was also beneficial in evaluating the effect of the input parameters on the output results. Then, according to Eqs. (21)-(23), the effects of the impact weight of all design variables on the desired output obtained through calculations are presented in Table 9. A comparison of the $S / N$ analysis results given in Figure 16 and those listed in Table 9 was made to select the appropriate levels of variables. Then, the optimization variables were selected to achieve the best design results for both average torque and torque ripple. Consequently, the 1-set level of $\Delta Y q_{2}$, 4-set level of $\Delta Y q_{1}$ and $k_{w q}$, and 5 -set level of $\Delta W B_{1}$ and $\Delta W B_{2}$ were selected as the optimum values.

Figure 17 presents the results obtained from the detailed analysis of the prototype SynRM. In case the scooter motor is used in vehicles, it must be able to produce its maximum torque (at least two to three times) when starting from zero to base speed to overcome the initial inertial force $[12,31,32]$. Therefore, the motor needs a high starting current and torque. However, the amount of this current for the synchronous reluctance 


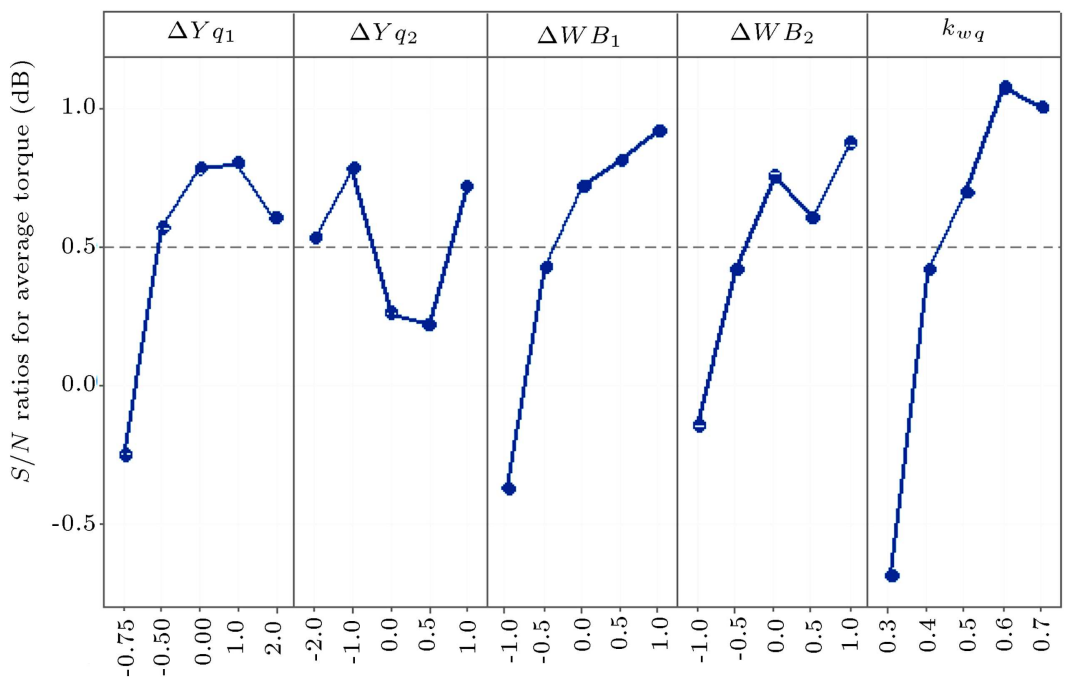

Signat-to-noise: Larger is better

(a)

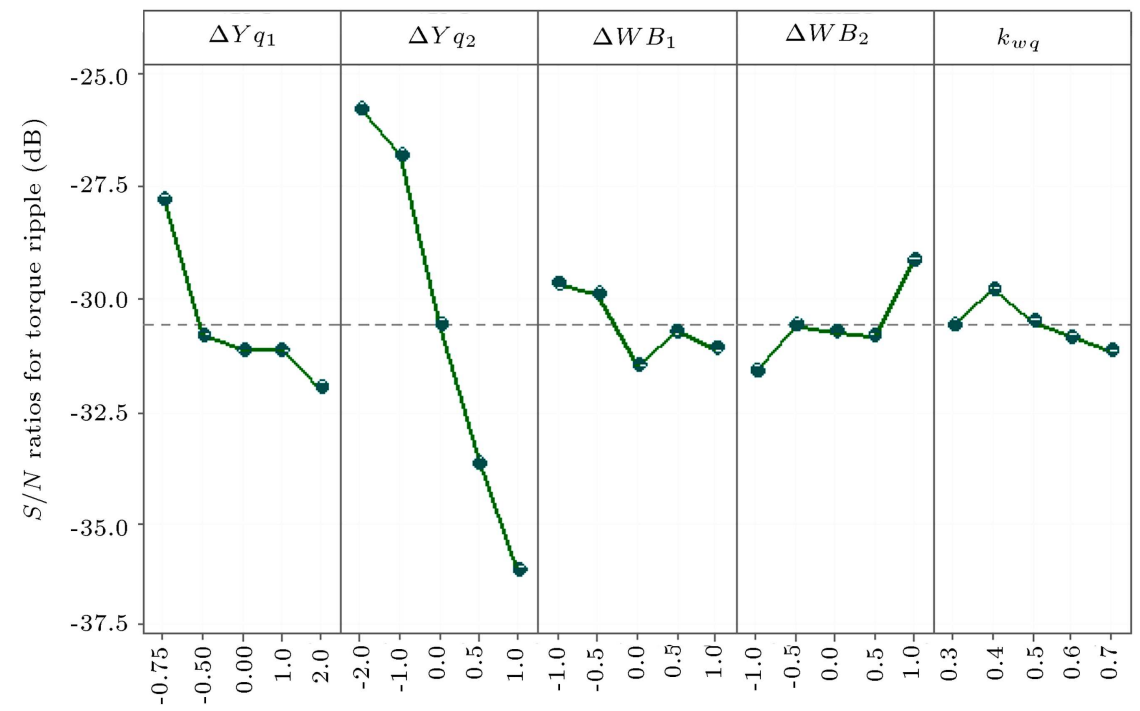

Signat-to-noise: Smaller is better

(b)

Figure 16. $S / N$ ratio of the optimization parameters for: (a) Average torque and (b) torque ripple.

Table 8. Assignment of control factors and levels.

\begin{tabular}{cccccccc}
\hline No. & $\boldsymbol{\Delta} \boldsymbol{Y} \boldsymbol{q}_{\mathbf{1}}$ & $\boldsymbol{\Delta} \boldsymbol{Y} \boldsymbol{q}_{\mathbf{2}}$ & $\boldsymbol{\Delta} \boldsymbol{W} \boldsymbol{B}_{\mathbf{1}}$ & $\boldsymbol{\Delta} \boldsymbol{W} \boldsymbol{B}_{\mathbf{2}}$ & $\boldsymbol{k}_{\boldsymbol{w q} \boldsymbol{q}}$ & $\boldsymbol{T}_{\boldsymbol{a v g}}(\mathbf{N} . \mathbf{m})$ & $\boldsymbol{T}_{\text {ripple }}(\%)$ \\
\hline 1 & 1 & 1 & 1 & 1 & 1 & 0.68 & 14.7 \\
2 & 1 & 2 & 2 & 2 & 2 & 0.99 & 10.8 \\
3 & 1 & 3 & 3 & 3 & 3 & 1.02 & 27.9 \\
4 & 1 & 4 & 4 & 4 & 4 & 1.09 & 41.3 \\
5 & 1 & 5 & 5 & 5 & 5 & 1.15 & 48.4 \\
& & & & & & & \\
21 & 5 & 1 & 5 & 4 & 3 & 1.19 & 19.9 \\
22 & 5 & 2 & 1 & 5 & 4 & 1.12 & 20.6 \\
23 & 5 & 3 & 2 & 1 & 5 & 1.04 & 48.4 \\
24 & 5 & 4 & 3 & 2 & 1 & 0.92 & 68.6 \\
25 & 5 & 5 & 4 & 3 & 1 & 1.11 & 72.6 \\
\hline
\end{tabular}


Table 9. Impact weight of design variables.

\begin{tabular}{ccc}
\hline Variable & $\begin{array}{c}\text { Impact weight on } \\
\text { average torque }\end{array}$ & $\begin{array}{c}\text { Impact weight on } \\
\text { average torque } \\
\text { ripple }\end{array}$ \\
\hline$\Delta Y q_{1}$ & $14.63 \%$ & $9.33 \%$ \\
$\Delta Y q_{2}$ & $7.62 \%$ & $82.47 \%$ \\
$\Delta W B_{1}$ & $22.36 \%$ & $2.15 \%$ \\
$\Delta W B_{2}$ & $11.98 \%$ & $5.6 \%$ \\
$k_{w q}$ & $43.41 \%$ & $0.46 \%$ \\
\hline
\end{tabular}

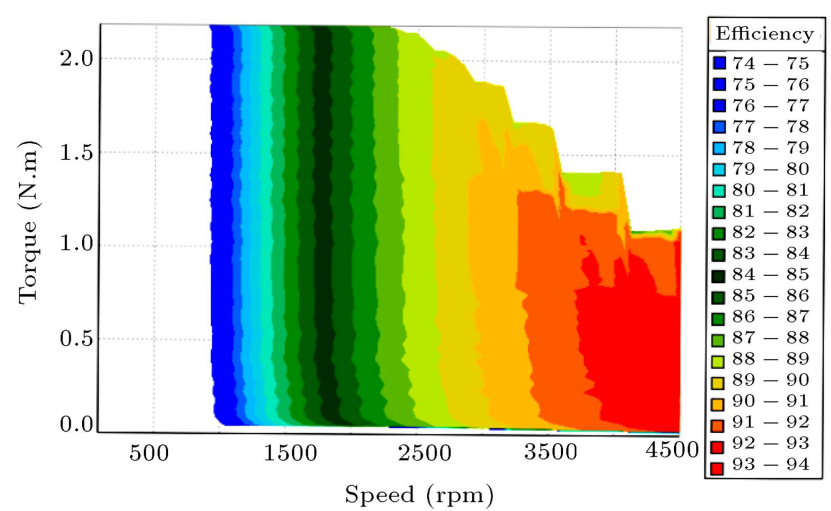

Figure 17. Efficiency map for prototype motor.

motor is less than that of the same current for the induction motor. Figure 17 presents an area in the efficiency map that determines the torque limit at the $1500 \mathrm{rpm}$ speed.

\section{Thermal analysis}

Finally, to ensure a safe operation of the selected motors at powers less than $300 \mathrm{~W}$ (Case 1) and also up to $1 \mathrm{hp}$ (Case 6), thermal analysis should be done. Based on Figure 18, the hotspots of the two cases are around the slots of the stator taking the maximum values of 50 and 106 degrees of centigrade, respectively. These values are acceptable based on the insulation class of the used materials.

\section{Prototyping and experimental setup}

A six-pole SynRM prototype was manufactured to be tested and then, its output torque value is compared with the FEM simulation results.

Then, the proposed strategy was evaluated. Figure 19 shows the different parts of this prototype. The stator is fixed to one side of the motor housing with three strong rods, and the rotor is mounted on a central shaft which is on a bearing ready to be connected to the load. The final test was performed to confirm the analytical results and FEM.

The prototype is tested in a laboratory equipped with the ABB ACS140 Multi-drive system. The result-

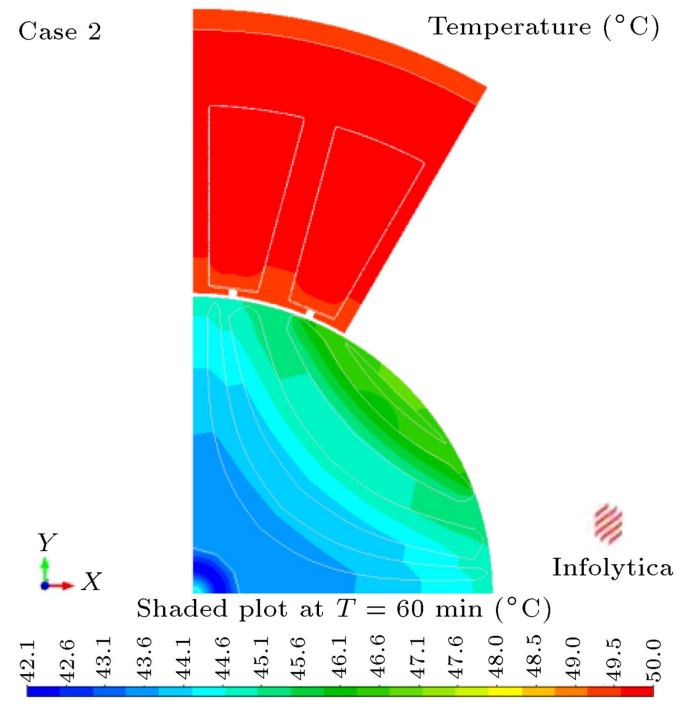

(a)

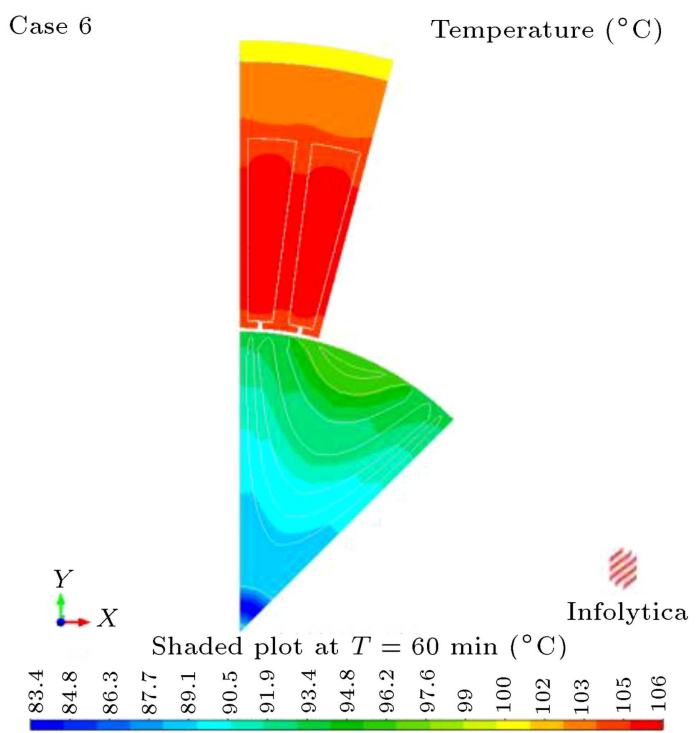

(b)

Figure 18. Temperature distribution of (a) Case 1 SynRM and (b) Case 6 SynRM.

ing specifications of the prototype SynRM are listed in Table 10. Figure 20 shows a comparison of the torque measured by FEA at different angles of the rotor at the nominal peak current of $10 \mathrm{Amps}$ and nominal speed of $1500 \mathrm{rpm}$. In this figure, the difference between the experimental and simulation results can be attributed to the inaccuracy of calculations and practical measurements as well as utilization of materials with real properties. In the experimental test results, compared to the FEA results, the average torque and torque ripple were reduced by $11 \%$ and $14 \%$, respectively, which could be attributed to the machining operation and created holes within the rotor and stator during the motor assembling and extra weight imposed on the external rotor by the aluminum shell for mechanical connection to the motor shaft. 


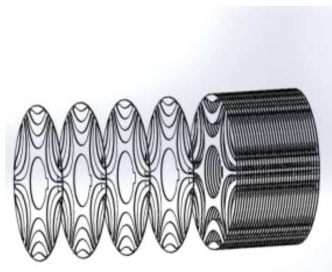

(a)

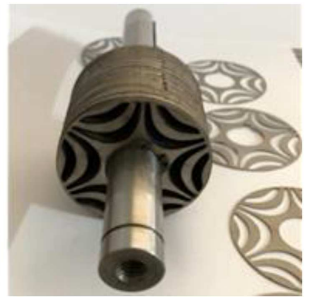

(b)

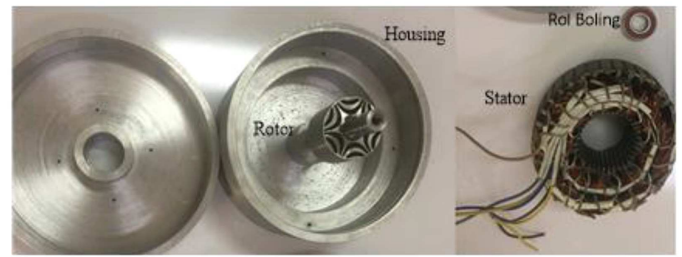

(c)

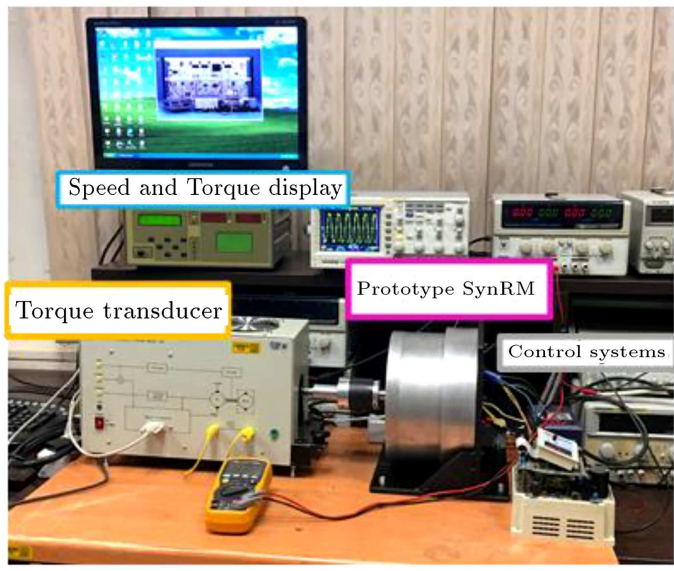

(d)

Figure 19. Different parts of SynRM: (a) Exploded view of the rotor, (b) lamination of the rotor, (c) main parts of motor, and (d) experimental test-setup.

Table 10. Specifications of the prototype motor.

\begin{tabular}{clc}
\hline Parameter & Definition & Value \\
\hline$P_{o}$ & Output power & $0.15 \mathrm{~kW}$ \\
$N_{s}$ & Rated speed & $1500(\mathrm{rpm})$ \\
$P . F$ & Power factor & 0.6 \\
$\boldsymbol{\eta}$ & Motor efficiency & 0.83 \\
Ploss & Total losses & $28 \mathrm{~W}$ \\
$P_{c u}$ & Stator copper losses & $21 \mathrm{~W}$ \\
$p c$ & Core loss & $5.3 \mathrm{~W}$ \\
$P_{f}$ and $W$ & Friction and wind age losses & $1.75 \mathrm{~W}$ \\
$I_{P}$ & Phase Current & $10(\mathrm{~A})$ \\
Copper $_{w}$ & Copper weight & $0.8 \mathrm{~kg}$ \\
Stator $_{w}$ & Stator core weight & $1.9 \mathrm{~kg}$ \\
Roto $_{w}$ & Rotor core weight & $1.2 \mathrm{~kg}$ \\
kst & Laminations stacking factor & 0.95 \\
\hline
\end{tabular}

\section{Conclusion}

The current study aimed to develop different designs of synchronous reluctance motor (SynRM) for electric scooter motors considering the geometrical dimensions

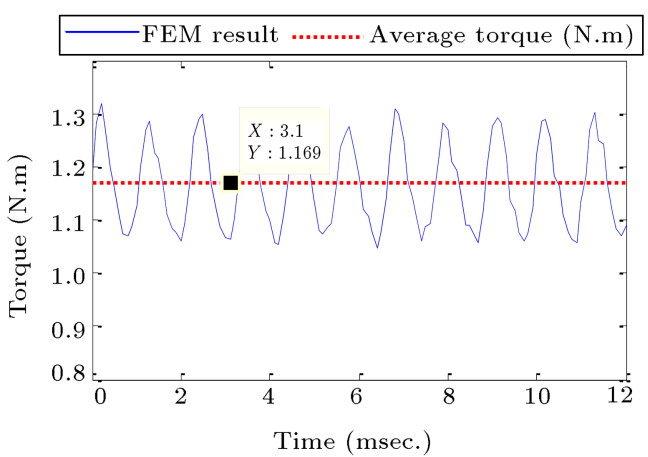

(a)

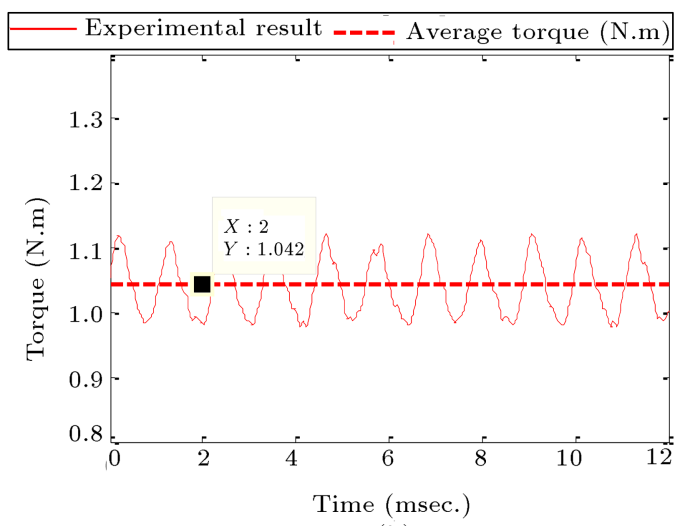

(b)

Figure 20. Torque of SynRM: (a) FEA result and (b) experimental result.

imposed by the shape of the scooter ring. To this end, it took into account the design requirements regarding the electromagnetic and mechanical issues of the motor with average high torque and low torque ripple. Throughout the study, first, an analytical method was developed using the concept of variable reluctance in SynRM based on the similarity between the flux line and shape of flux barriers. Accordingly, six motors with the same dimensions and six different rotors were selected from all possible cases. Then, the optimal shape of the flux barriers in the rotor of each motor was determined based on a multiplestep design including the Taguchi optimization method and sensitivity analysis. In all stages of the tests, the effects of changes in the effective parameters on the motor performance were evaluated by FEM analysis, and the percentage of the impact weight of each of these parameters on the output objective function was determined. In order to effectively employ the optimization method, all selected synchronous reluctance motors were optimized, and the results of both average torque and torque ripple were compared with those of the initial designs. Finally, thermal analyses were done to confirm the proper operation of the motor at the rated currents of the two specified SynRMs. The experimental results of a prototype six-pole SynRM validated the accuracy of the proposed design method. 


\section{References}

1. S̆tumberger, G., Hadžiselimović, and M., S̆tumberger, B. "Comparison of capabilities of reluctance synchronous motor and induction motor", Journal of Magnetism and Magnetic Materials, 304(2), pp. 835837 (Sept. 2006).

2. Fratta, A., Vagati, A., Villata, F., et al. "Design comparison between induction and synchronous reluctance motors", In Proc. 16th ICEM, pp. 329-334 (Sep. 6-8, 1994).

3. Yang, Y., Castano, S.M., Yang, R., et al, "Design and comparison of interior permanent magnet motor topologies for traction applications", IEEE Transactions on Transportation Electrification, 3(1), pp. 86-97 (2016).

4. Zhang, X., Zeng, L., Pei, R. "Designing and comparison of permanent magnet synchronous reluctance motors and conventional motors in electric vehicles", International Conference on Electrical Machines and Systems (ICEMS), pp. 202-205 (2018).

5. Baek, J., Reddy Bonthu, S., Choi, S. "Design of fivephase permanent magnet assisted synchronous reluctance motor for low output torque ripple applications", IET Electr. Power Appl. The Institution of Engineering and Technology, 10(5), pp. 339-346 (June 2016).

6. Shen, X.J., Cai, S., Hao, H., et al. "Investigation on torque ripple of synchronous reluctance machine with square-wave drive", International Conference on Electrical Machines and Systems (ICEMS), IEEE, pp. 1-9 (2017).

7. Rajabi Moghadam, R. "Synchronous reluctance machine (SynRM) in variable speed drives (VSD) applications", Doctoral Thesis, KTH Royal Institute of Technology Universities (2011).

8. Xu, M., Liu, G., Zhao, W., et al. "Minimization of torque ripple in ferrite-assisted synchronous reluctance motors by using asymmetric stator", AIP Advances, 8(5), p. 056606 (May 2018).

9. Chen, Q., Yan, Y., Xu, G., et al. "Principle of torque ripple reduction in synchronous reluctance motors with shifted asymmetrical poles", IEEE Journal of Emerging and Selected Topics in Power Electronics, 8(3), pp. 2611-2622 (2019).

10. Ruba, M.F., Jurca, L. Czumbil, et al. "Synchronous reluctance machine geometry optimisation through a genetic algorithm based technique", IET Electr. Power Appl., 12(3), pp. 431-438 (Mar. 2018).

11. Maroufian, S. and Pillay, P. "Torque characterization of a synchronous reluctance machine using an analytical model", IEEE Trans. Transp. Electrif., 4(2), pp. 506-516 (Jan. 2018).

12. Dziechciarz, A. and Martis, C. "Magnetic equivalent circuit of synchronous reluctance machine", Conference Paper ELEKTRO, pp. 500-503 (May 2016).

13. Rajabi Moghaddam, R., Magnussen, F., and Sadarangani, C. "A FEM investigation on the synchronous reluctance machine rotor geometry with just one flux barrier as a guide toward the optimal barrier's shape", In Proc. IEEE Eurocon, pp. 663-670 (May 1823 2009).

14. Isaac, F.N., Arkadan, A.A., Russell, A.A., et al. "Effects of anisotropy on the performance characteristics of an axially laminated anisotropic-rotor synchronous reluctance motor drive system", IEEE Transactions on Magnetics, 34(5), pp. 3600-3603 (Sept. 1998).

15. Jong Bin, I., Wonho, K., and Kwangsoo, K. "Inductance calculation method of synchronous reluctance motor including iron loss and cross magnetic saturation", IEEE Transactions on Magnetics, 45(6), pp. 2803-2806 (June 2009).

16. Nabil, M., Allam, S.M., and Rashad, E.M. "Modeling and design considerations of a photovoltaic energy source feeding a synchronous reluctance motor suitable for pumping systems", Ain Shams Engineering Journal, 3(4), pp. 375-382 (December 2012).

17. Aghazadeh, H., Afjei, E., and Siadatan, A. "Comprehensive design procedure and manufacturing of permanent magnet assisted synchronous reluctance motor", International Journal of Engineering, IJE, 32(99), pp. 1299-1305 (Sept. 2019).

18. Rajabi Moghaddam, R. and Gyllensten, F. "Novel high-performance SynRM design method: An easy approach for a complicated rotor topology", IEEE Transactions on Industrial Electronics, 61(9), pp. 5058-5065 (Sept. 2014).

19. Vagati, A. "Synchronous reluctance electrical motor having a low torque ripple design", USA Patent No. $5,818,140$, Oct. 6 (1998).

20. Vagati, A., Pastorelli, M., Francheschini, G., et al. "Design of low torque-ripple synchronous reluctance motors", IEEE Trans. on Industry Applic., 34(4), pp. 758-765 (July-Aug 1998).

21. Rajabi Moghaddam, R., Magnussen, F., and Sadarangani, C. "Novel rotor design optimization of synchronous reluctance machine for low torque ripple", In Proc. 20th ICEM, pp. 720-724 (Sept. 2-5 2012).

22. Deshpande, Y. and Toliyat, H. "Design of an outer rotor ferrite assisted synchronous reluctance machine (Fa-SynRM) for electric two wheeler application", IEEE Energy Conversion Congress and Exposition (ECCE), Conference Paper, pp. 3147-3154 (Nov. 2014).

23. Mun Song, B., Chan, K., and Young Choi, J. "Design of an outer-rotor type permanent magnet motor for electric scooter propulsion system", International Power Electronics Conference-ECCE ASIA, pp. 27362742 (2010).

24. Mathews, J.H. and Howell, R.W., Complex Analysis for Mathematics and Engineering, 4th Ed., Jones and Bartlett Publishers, ISBN 0-7637-1425- 9 (2001).

25. Ruba, M., Jurca, F., Czumbil, L., et al. "Synchronous reluctance machine geometry optimisation through a genetic algorithm based technique", IET Electr. Power Appl., 12(3), pp. 431-438 (Mar. 2018). 
26. Vagati, A., Franceschini, G., Marongiu, I., et al. "Design criteria of high performance synchronous reluctance motors", Industry Applications Society Annual Meeting, Conference Record of the IEEE, 4(9), pp. 6673 (Oct. 1992).

27. Aghazadeh, H., Afjei, E., and Siadatan, A. "Sizing and detailed design procedure of external rotor synchronous reluctance machine", IET Electr. Power Appl., The Institution of Engineering and Technology, 13(8), pp. 1105-1113 (Sept. 2019).

28. Fratta, A., Vagati, A., and Villata, F. "On the evolution of A.C. machines for spindle drive applications", Industry Applications, IEEE Transactions on, 28(5), pp. 1081-1086 (Sept.-Oct. 1992).

29. Taghavi, S.M. and Pillay, P. "A mechanically robust rotor with transverse laminations for a wide-speedrange synchronous reluctance traction motor", IEEE Transactions on Industry Applications, 51(6), pp. 4404-4414 (November/December 2015).

30. Taghavi, M. "Design of synchronous reluctance machines for automotive applications", Doctoral Thesis, Concordia University (March 2015).

31. Ajamloo, A., Mohammadi, A., Ghaheri, A., et al. "Multi-objective optimization of an outer rotor BLDC motor based on Taguchi method for propulsion applications", In 10th International Power Electronics, Drive Systems and Technologies Conference (PED$S T C)$, pp. 34-39, IEEE (2019).

32. Ajamloo, A., Mohammadi, A., Ghaheri, A., et al. "Non-linear analytical modelling and optimization of a $12 / 8$ rotor excited flux-switching machine", IET
Electric Power Applications, 14(9), pp. 1592-1603 (2020).

\section{Biographies}

Seyed Reza Salehinia is a PhD Candidate at Shahid Beheshti University. He received his MSc degree from Islamic Azad University, Najafabad Branch, Iran. His research interests are power electronics, switched reluctance machine designs, numerical analysis, and synchronous motors and drives.

Seyed Ebrahim Afjei received his BSc degree in Electrical Engineering from University of Texas in 1984, MSc degree in Electrical Engineering from University of Texas in 1986, and PhD degree from New Mexico State University, Las Cruces in 1991. He is currently a Professor at the Department of Electrical Engineering, Shahid Beheshti University, Tehran, Iran. His research interests are switched reluctance motor drives and power electronics.

Arsalan Hekmati received the BS, MS, and PhD degrees from the Sharif University of Technology, Tehran, Iran, in 2005, 2007, and 2011, respectively, all in Electrical Power Engineering. From 2011 to 2012, he was a Post-Doctoral Research Fellow in the Sharif University of Technology. His current research interests include superconducting power devices, insulation and highvoltage systems, and electric machinery, particularly transformers. 